Vol. 24, No. 3, Juli 2021, hlm. 391-400

p-ISSN: 1410-9344; e-ISSN: 2549-5631

WARTA LPM

homepage: http://journals.ums.ac.id/index.php/warta

\title{
Penguatan Keterampilan Berbasis Industri Perhotelan melalui Program Holistic pada Masyarakat Lulusan SMA/SMK di Provinsi Bali
}

\author{
${ }^{1}$ Kadek Ayu Ekasani, ${ }^{2}$ Putu Sabda Jayendra, ${ }^{3}$ I Nyoman Sudiarta, ${ }^{4}$ Made Arya Astina, ${ }^{5}$ I Made \\ Hadi Purnantara \\ Institut Pariwisata dan Bisnis Internasional \\ Email: ${ }^{1}$ ekasani@stpbi.ac.id, ${ }^{2}$ sabda@stpbi.ac.id, ${ }^{3}$ sudiarta@stpbi.ac.id, ${ }^{4}$ arya.astinamade@gmail.com, \\ ${ }^{5}$ hdpurnantara@gmail.com
}

\section{Article Info}

Submitted: 10 December 2020

Revised: 4 March 2021

Accepted: 8 April 2021

Published: 20 July 2021

Keywords: hotel, on the job training, holistic

Kata kunci: hotel, on the job training, holistic

\section{Abstract}

Skills are very needed by someone who worked in the hotel industry. Graduates from senior high school or vocational school who have attended some training at LPK (private training institution) need real industry skills before they really work in the industry. One of the activities to implement the students' need is on the job training. In the other side, the Covid-19 pandemic caused many hotels closed and make some LPK difficult to find the job training for their students. For this reason, IPB Internasional in collaboration with IHGMA creates a HOLISTIC program which aims to help graduates (SMA/K) gain OJT experience in the hospitality industry. The training participants were drawn from 3 famous tourism regions in Bali province, namely Ubud, Legian and Seminyak. In 13 days of training, the participants get handson theoretical and practical experience from hospitality practitioners in many departments, such as food and beverage service, food production, bartender and housekeeping departments. As a result of this training, the participants gained working experience in the industry, as well as various knowledge about hotel professionalism, career opportunities, motivation and support from hotel practitioners so that the participants have great optimism that the tourism sector will develop in the future.
Abstrak
Keterampilan (skill) dalam industri perhotelan sangat diperlukan bagi seseorang untuk memenuhi tuntutan kerja di dunia industri. Para lulusan SMA/K yang telah mengikuti pelatihan di LPK memerlukan suatu pendalaman keterampilan dunia industri perhotelan sebelum mereka benar-benar terjun langsung ke industri. Salah satu kegiatan untuk memperdalam keterampilan tersebut adalah melalui pelaksanaan on the job training. Namun adanya pandemi Covid-19 menyebabkan banyak hotel yang tidak membuka kesempatan bagi LPK untuk melaksanakan on the job training. Hal inilah yang membuat 
Institut Pariwisata dan Bisnis Internasional bekerjasama dengan IHGMA membuat program HOLISTIC yang bertujuan untuk membantu para lulusan SMA/K mendapatkan pengalaman OJT di industri perhotelan. Para peserta pelatihan diambil dari 3 wilayah di Provinsi Bali yang memiliki daerah wisata favorit, yaitu Ubud, Legian, dan Seminyak. Dengan total pelaksanaan pelatihan adalah 13 hari, peserta pelatihan mendapat pengalaman teori dan praktik langsung dari para praktisi perhotelan baik dari departemen tata hidang (food and beverage service), tata boga (food production), bartender, dan tata graha (housekeeping). Hasil dari pelatihan ini, para peserta mendapatkan pengalaman langsung di industri, selain juga berbagai pengetahuan mengenai profesionalisme kerja di industri perhotelan, peluang karir di dunia industri perhotelan, serta motivasi dan dukungan dari praktisi hotel sehingga para peserta memiliki optimisme yang besar bahwa sektor pariwisata masih menjadi sektor yang menjanjikan kedepannya.

\section{PENDAHULUAN}

Provinsi Bali merupakan daerah yang sudah sangat dikenal sebagai destinasi wisata favorit, baik bagi wisatawan domestik maupun mancanegara. Keindahan alam dan kekayaan budaya merupakan daya tarik utama yang membuat Bali menjadi tujuan utama dari aktivitas perjalanan yang dilakukan oleh wisatawan. Kondisi ini tidak saja membuat beragam destinasi wisata yang dimiliki Bali menjadi semakin terkenal, namun dibarengi pula dengan tumbuh suburnya sektor-sektor industri, terutama yang berbasis perhotelan.

Hotel merupakan salah satu akomodasi yang mengalami peningkatan di Bali. Berdasarkan data dari Badan Pusat Statistik Provinsi Bali (2015), pada tahun 2010 jumlah hotel di Bali adalah 2.190, sedangkan pada tahun 2014 jumlah hotel di Bali mencapai 3.039 (Widiastuti dan Indrawati, 2018). Data tersebut dapat dilengkapi dengan data dari DPD Perhimpunan Hotel dan Restoran Indonesia (PHRI) Bali (2016) yang mencatat dari keseluruhan hotel berbintang dan non bintang total kapasitas kamar yang tersedia adalah 56.971 kamar (Wardani dkk, 2017: 65). Peraturan Menteri Pariwisata dan Ekonomi Kreatif Nomor Pm.53/Hm.001/Mpek/2013 menyebutkan terdapat penggolongan kelas hotel yang terdiri atas, hotel bintang satu, hotel bintang dua, hotel bintang tiga, hotel bintang empat, dan hotel bintang lima (Prihatno, 2017). Kriteria penggolongan tersebut didasarkan pada persyaratan dasar dan penilaian teknis operasional. Tingkat Penghunian Kamar (TPK) tertinggi pada hotel di Bali tahun 2015 dimiliki oleh hotel bintang lima sebanyak 73,56\% (Badan Pusat Statistik Provinsi Bali, 2015).

Berdasarkan data tersebut, tidaklah mengherankan jika masyarakat Bali sangat banyak yang menggantungkan hidupnya pada sektor pariwisata. Bahkan anak-anak usia sekolah banyak yang bercita-cita untuk bekerja di sektor pariwisata, terutama yang berbasis industri perhotelan. Suburnya industri perhotelan di Bali membuat peluang kerja di satu sisi bertambah luas, namun di sisi lain, kompetisi akan kompetensi semakin ketat. Skill atau keterampilan harus dilatih sedini mungkin agar mampu memenuhi tuntutan kerja di dunia industri. Menurut Dunnett's (dalam Kandou, Lengkong \& Sendow, 2016), skill merupakan kompetensi yang dibutuhkan dalam pelaksanaan suatu rangkaian tugas yang kian berkembang dari hasil pelatihan dan pengalaman. Keahlian tercermin dari seberapa baik kinerja seseorang dalam melaksanakan suatu kegiatan yang spesifik, seperti operasional peralatan, efektivitas komunikasi atau penerapan suatu strategi bisnis. Oleh sebab itu, kecenderungan generasi muda Bali akan memilih melanjutkan di Perguruan Tinggi yang berbasis ilmu pariwisata atau Lembaga Pelatihan Kerja (LPK) untuk memperdalam keterampilan yang dibutuhkan.

Namun pada tahun 2020 sektor pariwisata Bali menghadapi pukulan yang cukup berat dengan adanya pandemi Covid-19. Rilis data dari 
Badan Pusat Statistik Provinsi Bali, ekonomi Bali dalam dalam triwulan pertama 2020 tumbuh negatif, yaitu -1,14 persen, dibandingkan dengan kondisi tahun lalu pada triwulan I tahun 2019. Pertumbuhan minus ini di luar tren sebelumnya yang diduga kuat dipengaruhi pandemi Covid 19 yang memengaruhi pergerakan masyarakat secara individu ataupun secara sosial. BPS Provinsi Bali melaporkan, total jumlah kedatangan wisatawan mancanegara yang langsung ke Bali pada Maret 2020 sebanyak 156.876 kunjungan. Jumlah tersebut turun sebanyak 56,89 persen dibanding total kunjungan selama Februari 2020 yaitu sebanyak 363.937 kunjungan. Penurunan pada sektor pariwisata disimpulkan berdampak sistematis terhadap lapangan kerja dan usaha lainnya yang juga mengalami penurunan. Bahkan, tekanan terhadap ekonomi Bali pada triwulan I (JanuariMaret) 2020 disebut-sebut mengalami pukulan paling keras dan dalam selama empat tahun terakhir sejak 2017 (Paramita dan Putra, 2020).

Kondisi ini turut berimbas pada lulusan-lulusan SMA/SMK di Bali yang ingin memperdalam keterampilannya di dunia perhotelan. Di satu sisi profesionalisme kerja yang dibutuhkan memerlukan legalitas berupa sertifikat kompetensi dari LPK serta sertifikat On The Job Training yang dikeluarkan oleh hotel-hotel yang bekerjasama dengan LPK tersebut. On the Job Training merupakan pelatihan dasar yang dilakukan langsung di tempat kerja di mana karyawan ditempatkan sesuai dengan departement mereka masingmasing dengan tujuan untuk mengenalkan trainee secara langsung terkait seluk-beluk tugasnya di bawah bimbingan pengawas atau supervisor (Permatasari \& Chaniago, 2018). Pelatihan On The Job Training sangat berperan dalam memberikan pengalaman dan membantu mahasiswa dalam mengimplementasikan ilmu pengetahuan yang diperoleh di kampus atau institusi LPK ke dalam dunia kerja yang nyata serta berperan dalam membentuk kecakapan pola pikir dan kecermatan bertindak dalam memecahkan masalah yang ditemui pada lingkungan kerja (Hanifah, 2019). Di sisi lain dampak pandemi membuat banyak lulusan SMA/SMK di Bali memilih menunda program pelatihannya akibat keterbatasan finansial. Kondisi ini diperparah dengan fenomena penurunan kunjungan wisatawan ke Bali yang menyebabkan tidak dibukanya program On The Job Training di hotel-hotel, khususnya hotelhotel berbintang.

Fenomena tersebut yang menjadi latar belakang dirancangnya program pelatihan yang menjadi alternatif $O n$ The Job Training di masa pandemi Covid-19 ini. Program ini diberi nama HOLISTIC, yang merupakan singkatan dari Hotel On Board Learning and Integration Strategic Training Implementation Center. Sasaran dari pelaksanaan program ini adalah lulusan SMA/ SMK di Bali, terutama di daerah-daerah tujuan wisata yang terdampak pandemi. Tujuannya agar para lulusan SMA/SMK ini tetap dapat mendalami keterampilan yang berbasis industri perhotelan. Berdasarkan hasil observasi awal, lulusan SMA/SMK yang tidak dapat melanjutkan untuk memperdalam keterampilannya terkonsentrasi pada tiga wilayah yang pada masa sebelum pandemi yang menjadi daerah pariwisata favorit, antara lain; 1) kawasan Ubud, Kabupaten Gianyar, 2) kawasan Legian, Kuta, Kabupaten Badung, dan 3) kawasan Seminyak, Kuta, Kabupaten Badung. Pemilihan ketiga kawasan ini didasari pertimbangan bahwa wilayah tersebut merupakan destinasi wisata yang dikenal dan banyak dikunjungi oleh wisatawan serta memiliki ikon dan keunggulan masing-masing yang selalu menarik dikunjungi oleh wisatawan mancanegara maupun domestik (Astina \& Wijaya, 2019).

Pelaksanaan program HOLISTIC ini selama total 13 (tiga belas) hari, yaitu dalam rentang hari mulai tanggal 12 Oktober 2020 sampai dengan 12 November 2020. Dalam praktik pelatihannya berpartner dengan beberapa hotel yang berkualifikasi bintang 4 dan bintang 5 di Bali, dengan total ada 10 hotel. Selain berpartner dengan pihak hotel, program pelatihan HOLISTIC juga melibatkan beberapa mahasiswa Institut Pariwisata dan Bisnis Internasional dalam teknis pelaksanaannya. Para mahasiswa ini dipilih yang sudah mendapatkan praktik pelatihan di kampus, sehingga dalam pelaksanaan program HOLISTIC di hotel-hotel partner tersebut, diharapkan ikut mendampingi para peserta pelatihan dalam praktik di bagian bidang atau departementnya masing-masing. Hal ini juga dimaksudkan untuk memudahkan instruktur dari hotel dalam mengawasi dan memastikan agar materi 
yang diberikan dapat dikuasai oleh seluruh peserta pelatihan. Dengan demikian diharapkan keterampilan berbasis industri yang dibutuhkan oleh peserta pelatihan dapat dikuasai dengan baik, terutama di era pandemi Covid-19 ini.

\section{METODE}

Pelaksanaan program pelatihan HOLISTIC yang peserta pelatihannya sebanyak 204 orang merupakan lulusan SMA/SMK yang terkonsentrasi di beberapa daerah kawasan wisata, yaitu Ubud, Legian, dan Seminyak. Metode yang dipergunakan dalam menentukan calon peserta pelatihan yang akan diikutkan dalam program HOLISTIC ini adalah purposive. Purposive dilakukan dengan memilih atau menseleksi calon peserta dengan kriteriakriteria yang ditetapkan sendiri oleh tim pengabdian. Adapun beberapa pertimbangan yang dipergunakan adalah:

a. Calon peserta pelatihan berasal dari keluarga tidak mampu.

b. Calon peserta pelatihan berasal dari keluarga pekerja yang terdampak pandemi Covid-19.

c. Calon peserta pelatihan memiliki minat untuk melanjutkan kuliah di program studi yang berbasis industri.

d. Calon peserta pelatihan memiliki orientasi kerja di bidang hotelier.

e. Calon peserta pelatihan tidak sedang bersekolah/kuliah dan tidak memiliki pekerjaan.

f. Calon peserta pelatihan merupakan lulusan SMA atau SMK.

Program ini dilaksanakan dengan menggandeng partner hotel-hotel yang berkualifikasi bintang 4 dan bintang 5 di Bali yang berada dalam wilayah kawasan tersebut. Adapun hotel-hotel yang digandeng untuk bekerjasama antara lain:

a. Seres Ubud,

b. FuramaXclusive Ubud,

c. Rumah Luwih Beach Resort Gianyar,

d. J4 Hotel Legian,

e. Swiss-Belinn Legian,

f. Neo+ Kuta Legian,

g. Jambuluwuk Oceano Seminyak, h. Sense Hotel Seminyak,

i. Sovereign Tuban, dan

j. Rama Beach Resort and Villas Tuban.

Hotel-hotel yang tercantum di atas adalah hotel yang sudah tergabung dalam asosiasi IHGMA (Indonesian Hotel General Manager Association) yang memiliki visi, misi, dan tujuan yang sama dengan IPBI, yaitu untuk mencerdaskan generasi bangsa.

Metode pelatihan yang diberikan berupa teori dan praktik. Teori diberikan secara tatap muka dengan menggunakan auditorium atau meeting room di masing-masing hotel. Untuk teori mengenai seputar dunia industri perhotelan diberikan oleh General Manager (GM) dari masing-masing hotel. Teori diberikan selama dua hari dengan menekankan langsung kepada kesiapan dari para peserta terhadap kondisi hotel sekarang ini. Sementara dalam praktiknya dilaksanakan di outlet masing-masing hotel, yaitu outlet restaurant, outlet bar, outlet kitchen, dan outlet kamar hotel. Untuk praktik, instukturnya merupakan orang yang ahli di bidangnya dan disediakan pula oleh hotel, baik itu yang berkualifikasi Chef, Barista, FB Manager, dan Housekeeping Supervisor. Selama melaksanakan pelatihan, para instruktur hotel juga dibantu oleh mahasiswa dari kampus Institut Pariwisata dan Bisnis Internasional dengan langsung terlibat dalam mendampingi para peserta pelatihan, terutama dalam pengawasan dan memastikan agar semua petunjuk dari instruktur dapat diterima dengan baik. Mahasiswa IPBI yang dilibatkan di masing-masing hotel telah dibekali pendidikan dan keterampilan yang sesuai dengan bidangnya sehingga sudah mampu untuk membagi ilmu yang mereka dapat kepada para peserta pelatihan.

\section{HASIL DAN PEMBAHASAN}

\section{Persiapan dan Pembagian Grup Peserta Pelatihan}

Kegiatan HOLISTIC dimulai secara serentak pada tanggal 12 Oktober 2020 di semua hotel. Seminggu sebelum hari pelaksanaan, peserta pelatihan dibagi dalam beberapa grup. Grup ini diatur berdasarkan wilayah, asal peserta pelatihan, spesifikasi keahlian atau departemen yang dipilih, serta kapasitas di masing-masing 
hotel dalam menampung jumlah peserta dengan tetap mengikuti protap kesehatan yang telah ditetapkan oleh hotel dan physical distancing. Maka dari itu, jumlah grup yang diterima di masing-masing hotel tidaklah sama, ada hotel yang hanya mendapatkan 1 grup, dan ada pula yang mendapatkan 2 grup. Untuk memaksimalkan jumlah jam yang diterima oleh masing-masing peserta dengan tidak terlepas dari protokol kesehatan maka porsi pelatihan yang diberikan kepada peserta adalah 3 jam setiap harinya. Maka dari itu, grup pertama yang mendapat shift pagi pelaksanaan pelatihan dimulai pada pukul 09.00 WITA sampai dengan pukul 12.00 WITA, sedangkan grup kedua yang mendapat shift siang, pelaksanaan pelatihan dimulai dari pukul 13.00 WITA sampai dengan pukul 16.00 WITA. Dari total jumlah 204 peserta pelatihan, maka rincian grup yang tersebar di masing-masing hotel tersaji dalam tabel 1.

Sedangkan untuk rincian spesifikasi keahlian atau departemen yang dipilih secara garis besar terdiri atas 4 (empat) bidang keahlian, yaitu; 1) Tata Hidang (Food and Beverage Service/FBS), 2) Tata Boga (Food and Beverage Product/FBP), 3) Bartender, dan 4) Tata Graha (Housekeeping). Peminat keahlian Bartender menempati posisi terbanyak berjumlah 96 orang, disusul dengan Food and Beverage Service sebanyak 59 orang, Food and Beverage Product sebanyak 39 orang, dan Housekeeping sebanyak 10 orang. Adapun sebarannya di tiap-tiap hotel dapat dilihat pada tabel 2.

Tabel 1. Sebaran Jumlah Peserta Pelatihan pada Setiap Hotel

\begin{tabular}{|c|c|c|c|c|}
\hline \multirow{2}{*}{ No } & \multirow{2}{*}{ Nama Hotel } & \multicolumn{2}{|c|}{ Jumlah Peserta dalam Grup } & \multirow{2}{*}{ Jumlah } \\
\hline & & Grup 1 & Grup 2 & \\
\hline 1 & Seres Ubud & 15 & 15 & 30 \\
\hline 2 & FuramaXclusive Ubud & 14 & - & 14 \\
\hline 3 & Rumah Luwih Beach Resort Gianyar & 14 & - & 14 \\
\hline 4 & J4 Hotel Legian & 15 & - & 15 \\
\hline 5 & Swiss-Belinn Legian & 16 & 16 & 32 \\
\hline 6 & Neo+ Kuta Legian & 15 & - & 15 \\
\hline 7 & Jambuluwuk Oceano Seminyak & 16 & - & 16 \\
\hline 8 & Sense Hotel Seminyak & 14 & - & 14 \\
\hline 9 & Sovereign Tuban & 15 & 12 & 27 \\
\hline 10 & Rama Beach Resort dan Villas Tuban & 14 & 13 & 27 \\
\hline & JUMLAH & 148 & 56 & 204 \\
\hline
\end{tabular}

Tabel. 2 Sebaran Jumlah Peserta pada Tiap Hotel Berdasarkan Departement/Keahlian yang Diminati

\begin{tabular}{clccccc}
\hline No & Nama Hotel & FB Service & FB Product & Bartender & Housekeeping & Jumlah \\
\hline 1 & Seres Ubud & 4 & 6 & 20 & - & 30 \\
2 & FuramaXclusive Ubud & 4 & 4 & 6 & - & 14 \\
3 & Rumah Luwih Beach Resort Gianyar & 4 & - & - & 10 & 14 \\
4 & J4 Hotel Legian & 9 & 3 & 3 & - & 15 \\
5 & Swiss-Belinn Legian & 4 & 4 & 24 & - & 32 \\
6 & Neo+ Kuta Legian & 8 & 7 & - & - & 15 \\
7 & Jambuluwuk Oceano Seminyak & 4 & 4 & 8 & - & 16 \\
8 & Sense Hotel Seminyak & 10 & - & 4 & - & 14 \\
9 & Sovereign Tuban & 9 & 7 & 11 & - & 27 \\
10 & Rama Beach Resort dan Villas Tuban & 3 & 4 & 20 & - & 27 \\
\hline & $\quad$ JUMLAH & 59 & 39 & 96 & 10 & $\mathbf{2 0 4}$ \\
\hline
\end{tabular}


Satu minggu sebelum dimulainya program pelatihan HOLISTIC ini, para peserta pelatihan dibuatkan grup di media sosial Whatsapp untuk mempermudah koordinasi terkait hal-hal yang bersifat teknis. Melaluigrup Whatsapp inilah para peserta pelatihan mendapatkan pengumuman terkait penempatannya di hotel, sehingga masing-masing peserta sudah memiliki informasi yang jelas tentang lokasi hotel yang dituju. Lima hari sebelum pelaksanaan para peserta pelatihan diinstruksikan untuk datang ke hotel masing-masing untuk melakukan penjajakan lokasi atau observasi serta pembagian seragam praktik yang sesuai dengan bidang keahlian yang dipilih. Bagi peserta yang mengambil bidang Food and Beverage Service diinstruksikan untuk mengenakan kemeja putih dan bawahan berwarna gelap, sehingga pihak hotel hanya meminjamkan rompi waiter/waitress. Untuk yang mengambil bidang Food and Beverage Product diinstruksikan bagi yang lulusan SMK untuk mengenakan uniform kitchen yang sudah diperoleh saat di sekolah. Sedangkan bagi lulusan SMA umum mendapatkan uniform lengkap yang dipinjamkan oleh hotel. Bagi yang mengambil bidang Bartender tidak mendapatkan uniform khusus, hanya diinstruksikan menggunakan atasan kemeja putih dengan bawahan berwarna gelap. Sedangkan bagi peserta yang mengambil bidang Housekeeping dipinjamkan baju kaos training, sedangkan bawahannya berupa celana training diinstruksikan untuk menggunakan milik masing-masing. Dengan demikian, pada saat pelatihan dimulai, para peserta sudah mengenakan pakaian atau uniform praktiknya masing-masing.

Teknis pelaksanaan program pelatihan HOLISTIC total durasi adalah 13 hari yang diambil dalam rentang tanggal 12 Oktober 2020 sampai dengan tanggal 12 November 2020. Selama 13 hari pelatihan tersebut, pada 4 hari di minggu pertama peserta secara serentak memulai program di masing-masing hotel dengan pemberian materi baik teori dan praktik oleh General Manager hotel. Selanjutnya di minggu kedua, ketiga, dan keempat setiap hotel mengatur jadwal peserta pelatihan untuk datang ke hotel sebanyak 3 kali dalam seminggu, sesuai dengan pembagian shift grupnya. Jadwal setelah 4 hari pertama tersebut diatur secara fleksibel oleh hotel masing-masing. Program ini diakhiri tanggal 12 November 2020 dengan kegiatan penutupan dan penyerahan sertifikat kepada seluruh peserta pelatihan.

\section{Pelaksanaan Pelatihan HOLISTIC}

Seperti yang telah dipaparkan sebelumnya bahwa program pelatihan HOLISTIC yang pelaksanaannya secara serentak dimulai pada tanggal 12 Oktober 2020, di hari pertama, peserta pelatihan menerima materi pelatihan berupa teori mengenai dasar-dasar keterampilan dan profesionalisme yang berbasis industri perhotelan. Kegiatan ini bertempat di meeting room masing-masing hotel dengan pemateri langsung dari General Managernya. Adapun kegiatannya dapat dilihat pada gambar berikut.

Materi yang diberikan oleh pihak hotel terlebih dahulu sudah disesuaikan dengan kebutuhan dari para peserta pelatihan. Selain menerima materi tentang profesionalisme kerja di industri perhotelan, materi yang disampaikan juga berupa peluang karir di dunia industri perhotelan, serta berbagai motivasi dan dukungan kepada seluruh peserta terkait dengan dampak pandemi Covid-19 di dunia industri perhotelan. Seperti yang diketahui bahwa dampak pandemi Covid-19 sangat besar sekali terhadap dunia pariwisata, tidak hanya di Bali namun juga di seluruh dunia. Inilah yang membuat para pekerja di industri pariwisata dan perhotelan banyak yang dirumahkan ataupun tidak diperpanjang masa kerjanya. Maka dari itu, sangat penting bagi seluruh peserta pelatihan mendapatkan pemahaman, motivasi, dan dukungan dari pihak hotel langsung agar para

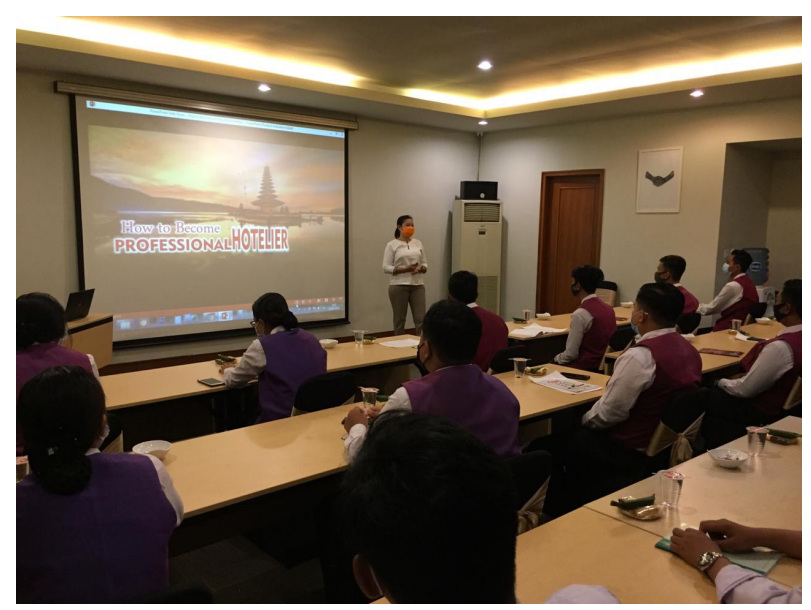

Gambar 1. Pemberian Materi Oleh General Manager Hotel 
peserta tetap optimis dan selalu bersemangat bahwa pandemi Covid-19 ini pasti bisa terlewati dengan segala upaya dari pemerintah untuk bisa membangkitkan kembali sektor pariwisata di Indonesia umumnya dan Bali pada khususnya.

Pada hari ke-2, para peserta pelatihan diberikan pemahaman mengenai seluk beluk outlet departement masing-masing. Pemahaman yang diberikan masih dalam ranah teoritis. Bedanya dengan hari pertama adalah, jika hari pertama pemahaman diberikan mengenai pengenalan industri perhotelan secara umum, maka pada hari ke- 2 lebih bersifat spesifik. Para peserta pelatihan dipecah grupnya sesuai spesifikasi departement yang dipilih. Adapun outlet-outletyang dituju tersebutadalah;1) Outlet Kitchen (untuk Food and Beverage Product), 2) Outlet Restaurant (untuk Food and Beverage Service), 3) Outlet Bar (untuk Bartender), dan 4) Outlet Guest Room (bagi Housekeeping).

Pada masing-masing outlet yang tersedia, sudah ada satu orang instruktur dari hotel yang dibantu oleh seorang mahasiswa yang membantu sebagai asisten instruktur. Instruktur kemudian memberikan pengetahuan mengenai segala sesuatu yang berkaitan dengan outlet departement masing-masing, dengan spesifikasi sebagai berikut.

1. Food and Beverage Product mendapat spesifikasi materi tentang Kitchen, antara lain, berbagai jenis peralatan di dapur, pengetahuan bahan-bahan makanan, jenis, dan dasar-dasar membuat appetizer, main menu, dessert, dan hygine sanitasi.

2. Food and Beverage Service mendapat spesifikasi materi tentang Restaurant antara lain peralatan untuk menyajikan makanan dan minuman, cara membawa hidangan ke meja tamu, cara meletakkan hidangan, table setup, dan bahasa Inggris yang biasa diucapkan saat melayani tamu asing.

3. Bartender mendapat spesifikasi materi tentang Bar, antara lain hygine sanitasi, jenis-jenis minuman, juggling bottles, mencampur minuman dan kadar alkohol, dan melayani tamu.

4. Housekeeping mendapat spesifikasi materi tentang Guest Room antara lain, bahanbahan chemical, dasar-dasar kebersihan, kerapian, serta kelengkapan kamar tamu, peralatan kebersihan, laundry, dan lain sebagainya.

Selain spesifikasi pengetahuan tersebut, secara umum setiap departement juga mendapatkan materi mengenai penerapan protokol kesehatan di masing-masing outlet. Hal ini dipandang perlu karena di masa pandemi Covid-19 setiap departement wajib menjaga kesehatan dan kebersihan, baik personal maupun kebersihan outlet masing-masing demi menjaga tingkat kepercayaan tamu yang berkunjung. Dalam pemberian materipun protokol kesehatan senantiasa diterapkan seperti terlihat dalam gambar berikut.

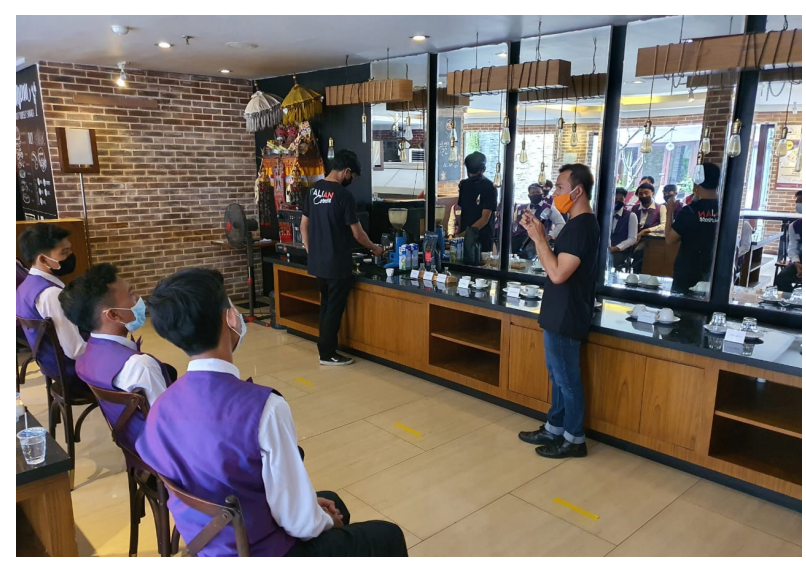

Gambar 2. Pemberian Materi Pelatihan di Outlet Restaurant

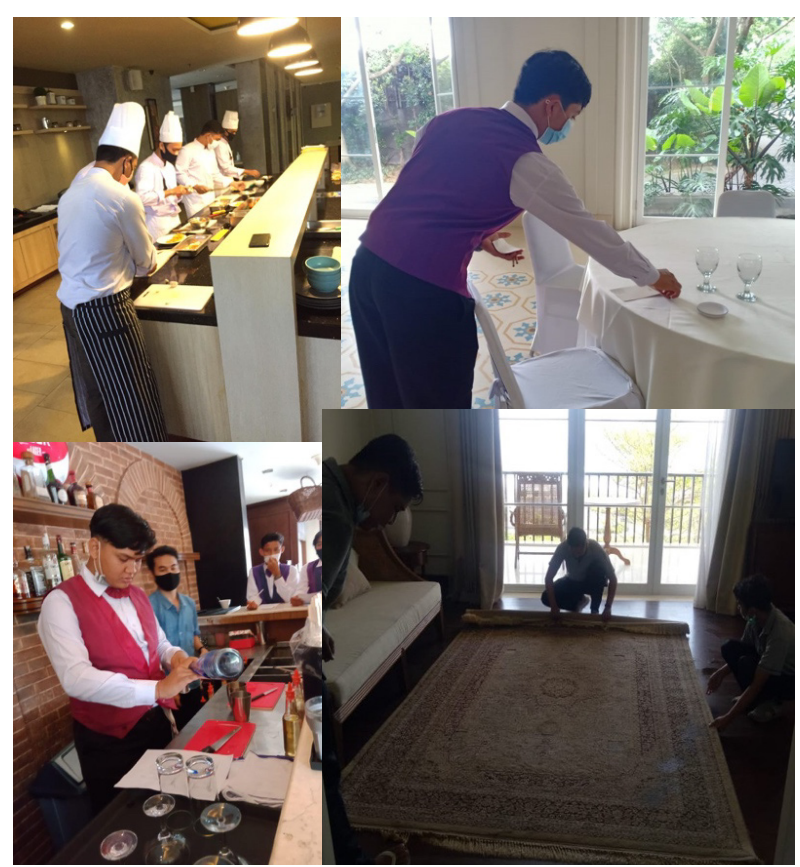

Gambar 3. Kegiatan Praktik Peserta HOLISTIC pada Masing-Masing Departement

Warta LPM, Vol. 24, No. 3, Juli 2021 
Pada hari ke-3 dan hari ke-4, para peserta pelatihan mulai melakukan praktik di outlet masing-masing. Dengan didampingi oleh instruktur masing-masing bidang serta satu orang mahasiswa sebagai asisten instruktur pada masing-masing outlet, para peserta pelatihan mendapatkan praktik yang intensif selama 4 jam. Beberapa kegiatan praktik tersebut dapat dilihat pada gambar 3 .

Setelah empat hari pertama, para peserta pelatihan kemudian diberikan jadwal yang diatur oleh hotel masing-masing. Dalam satu minggu, para peserta pelatihan dijadwalkan untuk datang tiga kali ke hotel, sesuai dengan pembagian shift-nya masing-masing. Masingmasing alokasi waktu pelatihan per-kedatangan yang diberikan adalah 3 sampai 4 jam. Selain menerima pelatihan praktik seperti hari ke-3 dan hari ke-4, para peserta pelatihan diwajibkan melakukan observasi mandiri tentang segala sesuatu yang berkaitan dengan departement keahliannya masing-masing. Checklist observasi disiapkan oleh panitia pengabdian yang muatan materinya mengarahkan peserta agar lebih jeli dan lebih mendalam dalam memahami standar kerja di outlet departement-nya masing-masing. Setiap departement berbeda-beda point-point muatan materi observasinya. Adapun checklist tersebut memuat materi tentang:

a. Standar dapur/restoran/bar counter/ kamar tamu.

b. Standar kelengkapan.

c. Standar karyawan.

d. Standar layanan.

e. Standar awal jam kerja.

f. Standar penyimpanan barang.

g. Standar pekerjaan utama.

h. Standar kerja tambahan.

i. Hal lain-lain yang perlu diuraikan lebih lanjut.

Dari chekclist-checklist tersebut di atas, meskipun sangat bervariasi bidang ilmu yang disesuaikan dengan departement yang dipilih, satu ilmu baru yang wajib diketahui seluruh peserta pelatihan adalah adaptasi protokol kesehatan. Peserta pelatihan wajib mengobservasi bagaimana setiap hotel mengadaptasikan himbauan protokol dari pemerintah serta implementasinya pada

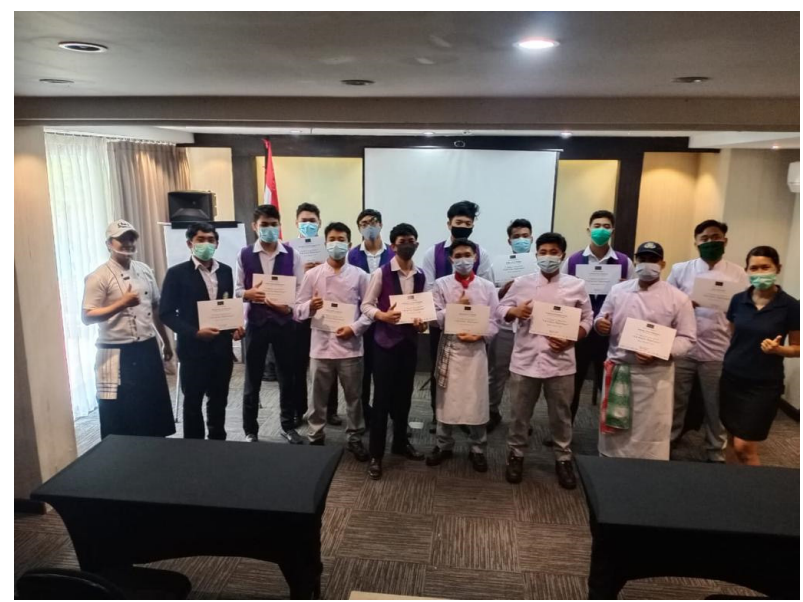

Gambar 4. Para Peserta Program HOLISTIC yang Telah Menerima Sertifikat

setiap departement masing-masing. Dengan demikian seluruh peserta pelatihan mendapat pemahaman secara holistik mengenai adaptasi dunia industri perhotelan di masa pandemi Covid-19. Keseluruhan kegiatan dinyatakan berakhir pada tanggal 12 November 2020.

Pada tanggal 19 November 2020, para peserta pelatihan diinstruksikan untuk datang kembali ke hotel masing-masing untuk seremonial penyerahan sertifikat. Sertifikat tersebut oleh hotel setara dengan 1 bulan pelatihan On The Job Training.

Sertifikat ini tentunya akan sangat berguna bagi para peserta pelatihan untuk digunakan sebagai bukti pengalaman saat melamar pekerjaan di industri. Keahlian tersebut tentunya sesuai dengan bidang keahlian yang telah dipelajarinya selama program HOLISTIC ini berjalan. Dengan demikian berakhirlah program HOLISTIC yang telah dirancang dan dijalankan, dan diharapkan kedepannya programprogram serupa dapat dirancang kembali untuk membantu insan-insan yang mengalami hambatan dalam mendalami dunia industri perhotelan akibat pandemi Covid-19.

\section{SIMPULAN}

Berdasarkan hasil dan pembahasan di atas dapat disimpulkan bahwa kegiatan HOLISTIC ini sangat bermanfaat bagi para peserta pelatihan yang berasal dari masyarakat lulusan SMK/A di daerah Ubud, Legian, Seminyak, Provinsi Bali. Para peserta mendapatkan pemahaman yang luas mengenai dunia industri perhotelan 
di masa pandemi ini. Selain ilmu tentang profesionalisme bekerja di hotel, peluang karir yang nantinya bisa diambil, serta motivasi dan dukungan dari para praktisi hotel bahwa sektor pariwisata masih tetap menjadi sektor yang menjanjikan untuk mendapatkan peluang karir yang bagus. Dukungan yang sangat penuh dari praktisi hotel untuk bisa memberikan ilmu dan keahlian di bidang perhotelan kepada para peserta pelatihan, yang mana pemberian materi langsung diberikan oleh para General Manager dan manager di masing-masing divisi.

Kegiatan ini kedepannya diharapkan dapat tetap dilaksanakan, tidak hanya dalam masa pandemi ini tetapi juga masa normal karena kegiatan ini dapat membantu masyarakat khususnya lulusan SMA yang memang belum pernah mendapatkan pendidikan dan keahlian di bidang perhotelan menjadi orang yang mempunyai keahlian khusus di bidang perhotelan. Kegiatan yang dilaksanakan kurang lebih selama 13 hari ini cukup untuk membuat para peserta pelatihan mendapatkan ilmu dan keahlian di bidang perhotelan sehingga pengalaman tersebut bisa dipakai sebagai syarat untuk mencari pekerjaan.

\section{PERSANTUNAN}

Tim pelaksana mengucapkan terima kasih kepada IHGMA (Indonesian Hotel General Manager Association) yang telah memberikan dukungan penuh kepada tim baik itu dari pemilihan hotel tempat dilaksanakannya kegiatan. Terima kasih kepada seluruh hotel yang terlibat dalam kegiatan ini, yaitu Seres Ubud, FuramaXclusive Ubud, Rumah Luwih Beach Resort Gianyar, J4 Hotel Legian, Swiss-Belinn Legian, Neo+ Kuta Legian, Jambuluwuk Oceano Seminyak, Sense Hotel Seminyak, Sovereign Tuban, Rama Beach Resort, dan Villas Tuban. Tim juga mengucapkan terima kasih kepada Rektor, Warek 3, dan seluruh jajarannya, mahasiswa IPBI-SPB yang terlibat dalam kegiatan ini, serta seluruh peserta pelatihan.

\section{DAFTAR PUSTAKA}

Astina, Made Arya., \& Wijaya, Anak Agung Gede. (2019). Perbandingan Nilai Budaya Karyawan Hotel di Seminyak dan Ubud. Jurnal Ilmiah Hospitality Management, 10(1), 64-76.

Badan Pusat Statistik (BPS). (2015). Jumlah Akomodasi, Kamar, dan Tempat Tidur yang Tersedia pada Hotel Bintang menurut Provinsi, 2000-2015, https://www.bps.go.id (diakses 7 Desember 2020).

Badan Pusat Statistik (BPS). (2015). Jumlah Kedatangan Wisatawan Per Tahun ke Bali menurut Pintu Masuk, 2010-2015, https://www.bps.go.id (diakses 7 Desember 2020).

Hanifah, Regina Dewi. (2019). Evaluasi Kinerja Mahasiswa Magang di Hotel Bintang 5 (*****). Jurnal Sadar Wisata, 2(2), 81-90.

Kandou, Yunita Lidya., Lengkong, Victor P.K., \& Sendow, Greis. (2016). Pengaruh Knowledge Management, Skill dan Attitude terhadap Kinerja Karyawan (Studi pada PT. Bank Sulutgo Kantor Pusat di Manado). Jurnal Berkala Ilmiah Efisiensi, 16(1), 147-158.

Paramita, I.B.G. \& Putra, I.G.G.P.A., (2020). New Normal Bagi Pariwisata Bali di Masa Pandemi Covid 19. Pariwisata Budaya: Jurnal Ilmiah Agama Dan Budaya, 5(2), pp.57-65.

Permatasari, I. W., \& Chaniago, H. (2018). Pengaruh On The Job Training terhadap Kinerja Karyawan (Studi di PT Kereta Api Indonesia (Persero) Kantor Pusat Bandung). Jurnal Riset Bisnis Dan Investasi, 4(2), 19-27. Retrieved from https://jurnal.polban.ac.id/an/article/view/1183.

Prihatno. (2018). Identifikasi Kebutuhan Kompetensi Sumber Daya Manusia Industri Perhotelan Kabupaten Bantul. Jurnal Media Wisata, 15(1), 513-530.

Wardani, R.K., Karta, N.L.P.A., Wiles, E. \& Widiastini, N.M.A., (2018). Pergeseran Marketing Strategy pada Hospitality Industry di Kabupaten Badung. Sekolah Tinggi Ilmu (STIE) Ekonomi Triatma Mulya, 23(1), pp.65-74. 
Ekasani, dkk - Penguatan Keterampilan Berbasis Industri Perhotelan ...

Widiastuti, N.W.S.\& Indrawati, K.R., (2018). Perbedaan Perilaku Kewargaan Organisasi berdasarkan Status Kerja Karyawan Hotel di Bali Ditinjau dari Kualitas Kehidupan Kerja. Jurnal Psikologi Udayana, 5(2), pp.378-402. 